University of Windsor

Scholarship at UWindsor

Mechanical, Automotive \& Materials

Department of Mechanical, Automotive \& Engineering Publications

Materials Engineering

$11-21-2019$

\title{
Environmentally Conscious Machining of Inconel 718: Surface Roughness, Tool Wear and Material Removal Rate Assessment
}

\author{
Sadaf Zahoor \\ University of Windsor \\ Fahad Ameen \\ University of Windsor \\ Walid Abdul-Kader \\ University of Windsor
}

Follow this and additional works at: https://scholar.uwindsor.ca/mechanicalengpub

Part of the Engineering Commons

\section{Recommended Citation}

Zahoor, Sadaf; Ameen, Fahad; and Abdul-Kader, Walid. (2019). Environmentally Conscious Machining of Inconel 718: Surface Roughness, Tool Wear and Material Removal Rate Assessment. The International Journal of Advanced Manufacturing Technology, 1.

https://scholar.uwindsor.ca/mechanicalengpub/20

This Article is brought to you for free and open access by the Department of Mechanical, Automotive \& Materials Engineering at Scholarship at UWindsor. It has been accepted for inclusion in Mechanical, Automotive \& Materials Engineering Publications by an authorized administrator of Scholarship at UWindsor. For more information, please contact scholarship@uwindsor.ca. 


\title{
Environmentally Conscious Machining of Inconel 718: Surface Roughness, Tool Wear and Material Removal Rate Assessment
}

\author{
Sadaf Zahoor ${ }^{1,2}$ (sadaf@uwindsor.ca) \& Fahad Ameen ${ }^{1}$ (ameen@uwindsor.ca) \& Walid Abdul-Kader ${ }^{1^{*}}$ (kader@uwindsor.ca) \& Jacqueline Stagner \\ (stagner@uwindsor.ca) \\ ${ }^{1}$ University of Windsor, Windsor, Ontario, Canada \\ ${ }^{2}$ University of Engineering and Technology, Lahore, Pakistan
}

\begin{abstract}
Flood cooling is a typical strategy used in the machining of difficult-to-cut materials where high temperatures are produced. Several environmental and health concerns are associated with the cutting fluids employed during this technique. Vegetable oil-based fluids appear to be the best substitute to conventional mineral/synthetic oils due to their environmentally friendly, biodegradable, renewable, and less toxic properties. Therefore, this paper attempts to establish an environmentally conscious, flood-cooling alternative through replacing conventional fluids with a synthetic vegetable ester-based (Mecagreen 450) biodegradable oil to investigate the machinability aspects of Inconel 718. In addition to the cooling environment, cutting speed $\left(v_{\mathrm{s}}\right)$, feed per tooth $\left(f_{\mathrm{z}}\right)$, and axial depth of cut $\left(\mathrm{a}_{\mathrm{p}}\right)$ have been used as control variables. A Taguchi $\mathrm{L}_{9}$ array has been selected for the design of experiments (DOE). Parametric effects and microscopic analyses have been carried out to investigate the three response parameters, i.e., surface roughness $\left(R_{a}\right)$, tool wear, and material removal rate (MRR). Tool wear analysis is further supplemented with scanning electron microscopy (SEM) and energy-dispersive spectroscopy (EDS).
\end{abstract}

Keywords: Inconel 718, environmental conscious cooling, biodegradable oil, surface roughness, tool wear, MRR, EDS

Sadaf Zahoor

Fahad Ameen

Walid Abdul-Kader (*Corresponding

Author)

J. Stagner

${ }^{1}$ University of Windsor, Windsor,

Ontario, Canada

${ }^{2}$ University of Engineering and

Technology, Lahore, Pakistan

*E-mail : kader@uwindsor.ca

\section{$1 \quad$ Introduction}

Nickel-based superalloys are a classification of hard-to-cut materials that offer an exceptional combination of properties like high corrosion resistance and high strength at elevated temperatures [1-2], thus, making this alloy an attractive choice for high-performance applications such as aeronautics, automotive, and biomedical. Despite the aforecited advantages, machinability of Ni-alloys is challenging for manufacturers due to their low thermal conductivity and high work-hardening characteristics [3-4]. Although, conventional machining of these advanced materials has an edge over non-conventional cutting methods in terms of low machining cost and high production rate [5-6], in the quest for achieving high productivity and quality of the machined surface, the tool life significantly suffers. The machining of these alloys involves an excessive amount of heat that cannot effectively be dissipated due to their low heat conductivity. Moreover, work hardened chips cause abrasive wear to the tool tip and ultimately reduce the tool life. To address these problems, modifying the cutting environment is a widely employed technique that has been studied in numerous published articles.

Zeliman et al. [7] investigate the wear mechanism during the wet and the dry turning of Inconel 718 with ceramic cutters. The study concludes that notch wear is the most dominant type of wear occurring during the turning operation and it becomes more significant in the case of dry machining. Similarly, Imran et al. [8] present a study of surface integrity evaluation for the machining of Inconel 718 subjected to wet and dry machining conditions. The 
results reveal that the cutting temperature and the use of coolant play a significant role in the microstructure alterations.

Conventional cutting fluids (mineral/synthetic) contain different types of high pressure chemical additives such as chlorine, sulphates, phosphates, and some biocides to maintain their functionality. It is argued that these contents account for not only the workers' health and environmental safety, but also for the cutting operation itself [1, 9-10]. For example, the presence of chlorine causes corrosion on the machined surface and ultimately reduces the life of the component. Also, these fluids cannot maintain their properties during the machining of hard-to-cut materials where high temperature is involved. In order to control all these issues, different alternatives are being employed; the most common ones are minimum quantity lubrication (MQL), high-pressure cooling, cryogenic cooling, and heatassisted and ultrasonic-assisted machining. For instance, Musfirah et al. [11] compare the results of cryogenic milling of Inconel 718 with dry conditions. Three cutting parameters, cutting speed $140-160 \mathrm{~m} / \mathrm{min}$, feed rate 0.15 $0.20 \mathrm{~mm} /$ tooth and radial depth of cut 0.2-0.4 mm, were employed during the cutting. The results show that cryogenic cooling reduces the cutting forces by $23 \%$ and improves the surface roughness by $88 \%$. Likewise, Mehta et al. [12] improve the process with respect to the cutting environment after performing a number of trials on turning of Inconel 718 under MQL, cryogenic, and cold air MQL. After comparing the results with dry machining, the study concludes that cold air MQL reduces the surface roughness and the tool wear by about $86 \%$ and $96 \%$, respectively. Leopardi et al. [13] conduct laser-assisted milling of Inconel 718. The study reveals that this approach reduces the cutting forces and the flank wear even at $800 \mathrm{~m} / \mathrm{min}$ cutting speed and $0.16 \mathrm{~mm} /$ tooth feed rate. Likewise, Hafiz et al. [14] perform ultrasonic machining of Inconel 718 with the aim to improve the surface quality of the machined component. The research concludes that $27 \mathrm{KHz}$ ultrasonic machining slightly improves the surface roughness.

In contrast, some studies have proved that the conventional cooling approach still offers better results for Inconel 718. Fernandez et al. [14] compare the results of conventional cooling methods with sustainable alternatives during the turning of Inconel 718. The work claims that cold air MQL, an ecological efficient choice, is capable of producing better surface roughness than usingdry conditions, but it is still unable to match the performance of conventional cooling. After performing surface integrity and tool wear analysis of Inconel 718 under conventional and cryoMQL environments, Iturbe et al. [16] add that the conventional cooling method is the best option for both the machinability and the surface integrity. The study shows that the tool life achieved with cryoMQL is three times shorter than that for the conventional method.

To compensate for the inadequacy of the cooling methods, the use of advanced cutting fluids such as vegetable and modified vegetable oil ester-based biodegradable fluids, solid lubricants and nanoparticles [1719] are studied. In context of the use of advanced cutting fluids, Pereira et al. [17] apply different biodegradable oils with MQL during the milling of Inconel 718. The research concludes that high oleic sunflower oil is a balanced option as it improves the $\mathrm{R}_{\mathrm{a}}$ by $15 \%$, with better environmental impacts. An author of this paper also contributed to green machining by giving a predictive study on Inconel 718 . Ameen [18] employed an artificial neural network (ANN) model to weigh the effects of biodegradable oil with flood lubrication during slot-milling. In another work, Marques et al. [19] analyze the surface integrity of Inconel 718 using solid lubricants with MQL as a hybrid cooling method. No significant effects can be observed on the $R_{a}$, the microstructure, and the residual stresses. While studying the effects of nanofluids with MQL on tool performance and chip morphology during the machining of Inconel 718, Hegab et al. [20] obtained better results when using multiwalled carbon nanotubes. Despite the fact that the nanoparticles can produce better results in machining, the risk associated with "nano-environmental health and safety (nano-EHS)" cannot be overlooked [21-22]. On the other hand, biodegradable oil is considered as an environmentally friendly cutting fluid [17, 23-24]. This is attributed to its biodegradability, high lubricity, low foaming characteristics, renewability, and cost effectiveness. High lubricity enables the vegetable esters to form a polar 
monolayer of carbon chains normal to the machined surface, thus, providing machining ease during cutting [24].

The above-discussed literature reveals that the research has been shifted from conventional cooling techniques towards unconventional methods like MQL, cryogenic MQL, and cold air MQL, etc. Additionally, the interest of researchers seems skewed towards the use of advanced cutting fluids. From the stream of advanced cutting fluids, the potential of biodegradable oil as a cutting fluid has been investigated with MQL. However, the effects of biodegradable fluid with the flood cooling method have not been thoroughly studied, which becomes the main motivation of this research. Furthermore, three process parameters - cutting speed $\left(v_{\mathrm{s}}\right)$, feed per tooth $\left(f_{\mathrm{z}}\right)$, and axial depth of cut $\left(a_{p}\right)$ - are considered as control variables. A Taguchi $L_{9}$ array is selected for the DOE. The surface roughness, tool wear, and material removal rate are considered as the response factors. Parametric effects analysis is carried out for all three response factors, and microscopic analysis is performed for tool wear which is further supplemented with SEM and EDS.

\section{$2 \quad$ Experimental Details}

Due to its diverse utilization and hard-to-machine nature, Inconel 718 is selected as the workpiece material for the present investigation. The spectroscopic results of chemical composition are given in Table 1. The thermo-mechanical properties of the alloy are also influential factors which affect its machinability during conventional cutting. Therefore, the important properties are presented in Table 2 and are consulted in the subsequent section to support the results.

Table 1: Inconel 718 chemical composition

\begin{tabular}{|l|c|c|c|}
\hline Element & Weight $(\%)$ & Element & Weight $(\%)$ \\
\hline $\mathrm{C}$ & 0.03 & $\mathrm{Nb}$ & 5.10 \\
\hline $\mathrm{Mn}$ & 0.08 & $\mathrm{Ta}$ & 0.005 \\
\hline $\mathrm{S}$ & 0.00001 & $\mathrm{~B}$ & 0.001 \\
\hline $\mathrm{Cu}$ & 0.06 & $\mathrm{Si}$ & 0.11 \\
\hline $\mathrm{Ni}$ & 53.51 & $\mathrm{Bi}$ & 0.000001 \\
\hline $\mathrm{Mo}$ & 3.00 & $\mathrm{P}$ & 0.008 \\
\hline $\mathrm{Cr}$ & 18.23 & $\mathrm{~Pb}$ & 0.00001 \\
\hline $\mathrm{Al}$ & 0.52 & $\mathrm{Co}$ & 0.14 \\
\hline $\mathrm{Ti}$ & 1.01 & $\mathrm{Fe}$ & Balanced \\
\hline
\end{tabular}

Table 2: Thermo-mechanical properties of Inconel 718 [25]

\begin{tabular}{|l|c|c|}
\hline Properties & Value & Unit \\
\hline Density & 0.297 & $\mathrm{lb}_{\text {/inch }}{ }^{3}$ \\
\hline Hardness & 36 & HRC \\
\hline Thermal Conductivity & 11.2 & W m-1 K-1 \\
\hline Melting Point & $1260-1336$ & ${ }^{\circ} \mathrm{C}$ \\
\hline
\end{tabular}

Slot milling was performed on the rectangular bars $(190 \times 63 \times 24 \mathrm{~mm})$ of Inconel 718 using a CNC machining center (LG-800 Hartford). For the flood lubrication, a Mecagreen 450 synthetic vegetable ester-based biodegradable oil as a cutting fluid with $6 \%$ concentration ratio $[23,26]$ was used at a flow rate of 0.05 liters/sec under 20 bar pressure, as suggested in literature [16]. The chemical composition of Mecagreen 450 is given in Table 3. Two nozzles, each of $2 \mathrm{~mm}$ diameter, were used at a $120^{\circ}$ angle to target the cutting zone, as shown in Figure 1(a-b). Titanium aluminum nitride (TiAlN) coated micro-grain carbide wiper inserts, clamped in a specially-designed, 2flute tool holder, were employed. These inserts possess lower affinity with Inconel 718, thus exhibiting good resistance to wear. Three process variables, the cutting speed $\left(v_{\mathrm{s}}\right)$, the feed per tooth $\left(f_{\mathrm{z}}\right)$, and the axial depth of cut $\left(a_{p}\right)$ and their levels, were carefully selected after a detailed literature review [11, 29] and are listed in Table 4, along with the other constant factors. The machinability of Inconel 718 has been probed in terms of surface roughness $\left(R_{a}\right)$, material removal rate, and tool wear.

Table 3: Chemical composition of Mecagreen 450

\begin{tabular}{|l|c|}
\hline Chemical Components & $(\%)$ \\
\hline Ethylene Glycol Monophenyl Ether & $10-20$ \\
\hline Isopropyl Oleate & $2.5-10$ \\
\hline 2,2', 2"-nitrilotriéthanol & $1-2.5$ \\
\hline 2-methylpentane-2,4-diol & $1-2.5$ \\
\hline Alpha-phenyl-omega-hydrox Ypoly & $1-2.5$ \\
\hline Oleic Acid, Ethoxylated & $1-2.5$ \\
\hline Fatty Alcohol Polyglycol Ether & $1-2.5$ \\
\hline
\end{tabular}

To take advantage of fewer trial runs without compromising the quality of data, a Taguchi L 9 array was used to perform the cutting tests on the superalloy. After machining the slot $(63 \times 9.7 \times 3 \mathrm{~mm})$ with new wiper inserts, the surface roughness of each slot was measured using a surface profilometer (WYKO NY 1100). During the experimentation, the machining time for each test run was recorded and the workpiece material was weighed before 
and after each slot. Using the recorded data, MRR was calculated using Equation 1.

$$
\operatorname{MRR}=(\mathrm{WB}-\mathrm{WA}) /\left(\rho_{\mathrm{m}} * \mathrm{t}\right) \mathrm{mm}^{3} / \mathrm{s}
$$

Where, WB and WA are the weights $(\mathrm{kg})$ of the workpiece before and after the milling, $\rho_{\mathrm{m}}$ is the density $\left(\mathrm{kg} / \mathrm{mm}^{3}\right)$ of the material, and $\mathrm{t}$ is the machining time (s) for each run.
Subsequently, tool wear was carefully measured using a stereomicroscope (AxioCam ERc 5s). Additionally, SEM and EDS, using an FEI Quanta 200F, were employed to scrutinize the causes of tool wear. The variable effects on the output attributes were analyzed and quantified using main-effects plots and ANOVA.

Table 4: Detail of control factors and constant parameters employed during the milling of Inconel 718

\begin{tabular}{|c|c|c|c|c|c|c|}
\hline \multirow[t]{2}{*}{ Level } & \multicolumn{3}{|c|}{ Control Factors } & \multicolumn{3}{|c|}{ Constant Parameters } \\
\hline & $\begin{array}{c}\text { Cutting Speed } \\
\left(v_{\mathrm{s}}\right) \\
(\mathrm{m} / \mathrm{min})\end{array}$ & $\begin{array}{c}\text { Feed per Tooth } \\
\left(f_{\mathrm{z}}\right) \\
(\mathrm{mm} / \text { tooth })\end{array}$ & $\begin{array}{l}\text { Axial Depth of Cut } \\
(\mathrm{ap}) \\
(\mathrm{mm})\end{array}$ & $\begin{array}{l}\text { Radial Depth of Cut } \\
\text { (mm) }\end{array}$ & $\begin{array}{c}\text { Tool Hang } \\
\text { (mm) }\end{array}$ & $\begin{array}{l}\text { No. of } \\
\text { Flutes }\end{array}$ \\
\hline 1 & 65 & 0.10 & 0.20 & 9.7 & 32 & 2 \\
\hline 2 & 80 & 0.15 & 0.30 & 9.7 & 32 & 2 \\
\hline 3 & 95 & 0.20 & 0.40 & 9.7 & 32 & 2 \\
\hline
\end{tabular}

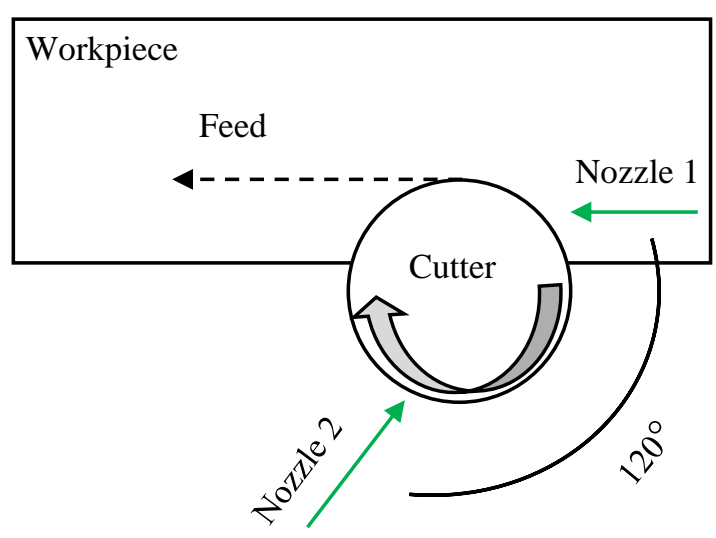

b

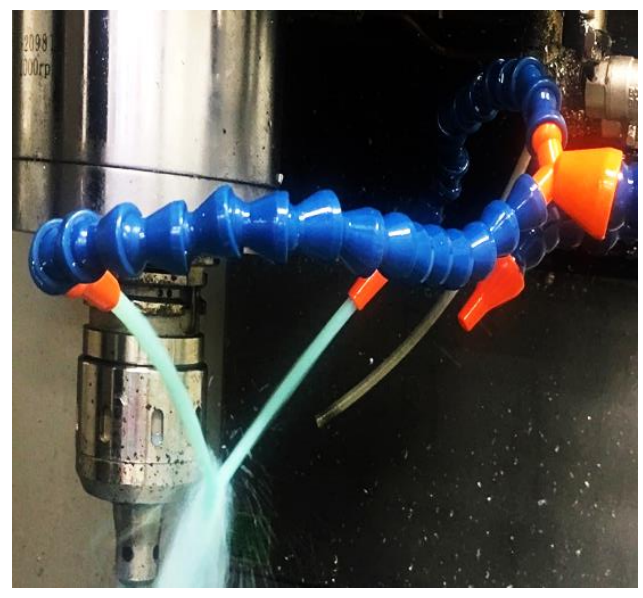

Fig. 1 (a-b): Pictorial view of lubrication set-up

\section{Experimental Results and Discussion}

With the recommended warm-up time (approximately five minutes), machining trials on Inconel 718 were performed according to the L9 array. After cutting, the surface roughness and flank wear were measured followed by calculating the material removal rate. The results are presented in Table 5. 
Table 5: Experimental results of surface roughness, material removal rate, and flank wear for Inconel 718, as per the $\mathrm{L}_{9}$ array

\begin{tabular}{|c|c|c|c|c|c|c|}
\hline $\begin{array}{l}\text { Test } \\
\text { Run }\end{array}$ & $\begin{array}{l}\text { Cutting Speed } \\
\left(v_{\mathrm{s}}\right) \\
(\mathrm{m} / \mathrm{min}) \\
\end{array}$ & $\begin{array}{c}\text { Feed per Tooth } \\
\qquad\left(f_{z}\right) \\
(\mathrm{mm} / \text { tooth }) \\
\end{array}$ & $\begin{array}{c}\text { Axial Depth of } \\
\text { Cut } \\
(\mathrm{ap}) \\
(\mathrm{mm}) \\
\end{array}$ & $\begin{array}{c}\text { Surface Roughness } \\
\left(\mathrm{R}_{\mathrm{a}}\right) \\
(\mu \mathrm{m}) \\
\end{array}$ & $\begin{array}{c}\text { Material Removal } \\
\text { Rate } \\
(\mathrm{MRR}) \\
\left(\mathrm{mm}^{3} / \mathrm{min}\right) \\
\end{array}$ & $\begin{array}{c}\text { Flank Wear } \\
\left(\mathrm{V}_{\mathrm{B}}\right) \\
(\mu \mathrm{m}) \\
\end{array}$ \\
\hline 1 & 65 & 0.10 & 0.20 & 0.544 & 527.90 & 8.95 \\
\hline 2 & 65 & 0.15 & 0.30 & 0.819 & 1091.25 & 14.06 \\
\hline 3 & 65 & 0.20 & 0.40 & 0.998 & 1668.63 & 15.98 \\
\hline 4 & 80 & 0.10 & 0.30 & 1.038 & 964.0 & 21.09 \\
\hline 5 & 80 & 0.15 & 0.40 & 1.546 & 1553.0 & 27.49 \\
\hline 6 & 80 & 0.20 & 0.20 & 1.690 & 1047.6 & 57.54 \\
\hline 7 & 95 & 0.10 & 0.40 & 1.596 & 1328.47 & 70.97 \\
\hline 8 & 95 & 0.15 & 0.20 & 1.835 & 990.97 & 90.70 \\
\hline 9 & 95 & 0.20 & 0.30 & 1.920 & 1619.79 & 101.50 \\
\hline
\end{tabular}

\subsection{Parametric Effects on Surface Roughness, $\left(R_{a}\right)$}

Figure 2 illustrates the 3D topographic images for the surface roughness $\left(\mathrm{R}_{\mathrm{a}}\right)$ of the milled slots under different cutting conditions. It can be visualized from the images that the tool marks and the uncut metal are the prominent
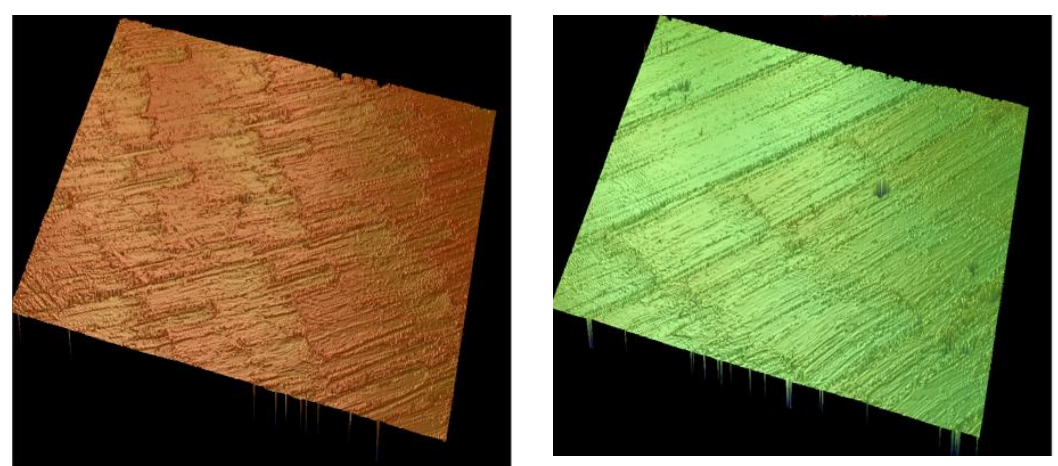

Test Run 1: $v_{\mathrm{s}} 65 \mathrm{~m} / \mathrm{min}, f_{\mathrm{z}} 0.10 \mathrm{~mm} / \mathrm{tooth}$, $a_{\mathrm{p}} 0.20 \mathrm{~mm}$

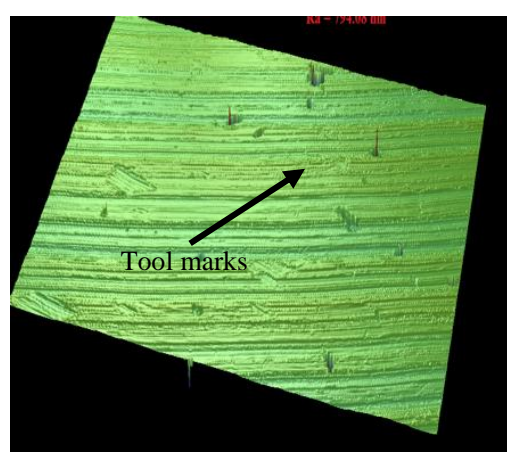

Test Run 4: $v_{\mathrm{s}} 80 \mathrm{~m} / \mathrm{min}, f_{\mathrm{z}} 0.10 \mathrm{~mm} /$ tooth, $\mathrm{a}_{\mathrm{p}} 0.30 \mathrm{~mm}$
Test Run 2: $v_{\mathrm{s}} 65 \mathrm{~m} / \mathrm{min}, f_{\mathrm{z}} 0.15 \mathrm{~mm} / \mathrm{tooth}$, $\mathrm{a}_{\mathrm{p}} 0.30 \mathrm{~mm}$

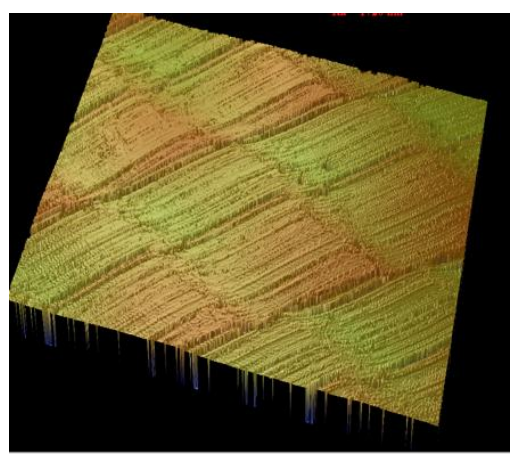

Test Run 5: $v_{\mathrm{s}} 80 \mathrm{~m} / \mathrm{min}, f_{\mathrm{z}} 0.15 \mathrm{~mm} / \mathrm{tooth}$, $\mathrm{a}_{\mathrm{p}} 0.40 \mathrm{~mm}$ features of the machined surface which deteriorated as the $v_{\mathrm{s}}$ and the $f_{\mathrm{z}}$ increased. The result is a coarse milled surface which is responsible for high values of peaks and valleys causing a rough surface finish. The $\mathrm{R}_{\mathrm{a}}$ values given in Table 5 also support the topographic findings.

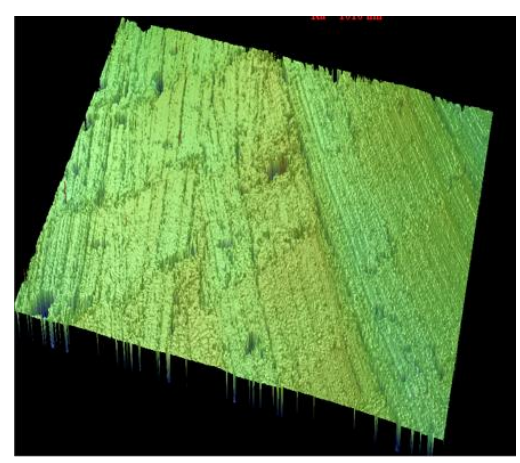

Test Run 3: $v_{\mathrm{s}} 65 \mathrm{~m} / \mathrm{min}, f_{\mathrm{z}} 0.20 \mathrm{~mm} / \mathrm{tooth}$, $a_{p} 0.40 \mathrm{~mm}$

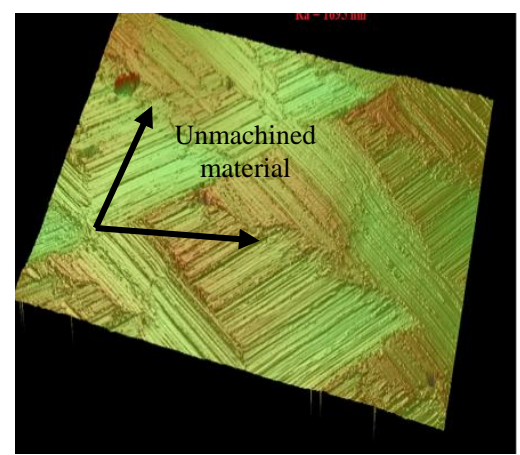

Test Run 6: $v_{\mathrm{s}} 80 \mathrm{~m} / \mathrm{min}, f_{\mathrm{z}} 0.20 \mathrm{~mm} / \mathrm{tooth}$, $\mathrm{a}_{\mathrm{p}} 0.20 \mathrm{~mm}$ 


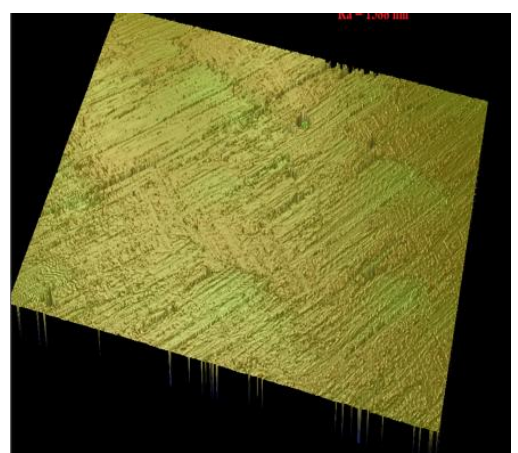

Test Run 7: $v_{\mathrm{s}} 95 \mathrm{~m} / \mathrm{min}, f_{\mathrm{z}} 0.10 \mathrm{~mm} /$ tooth, $\mathrm{a}_{\mathrm{p}} 0.40 \mathrm{~mm}$

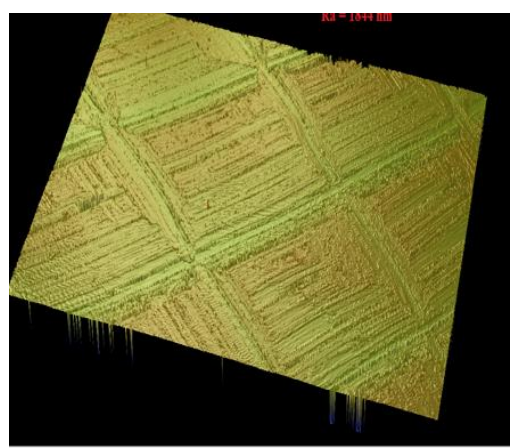

Test Run 8: $v_{\mathrm{s}} 95 \mathrm{~m} / \mathrm{min}, f_{\mathrm{z}} 0.15 \mathrm{~mm} /$ tooth, $\mathrm{a}_{\mathrm{p}} 0.20 \mathrm{~mm}$

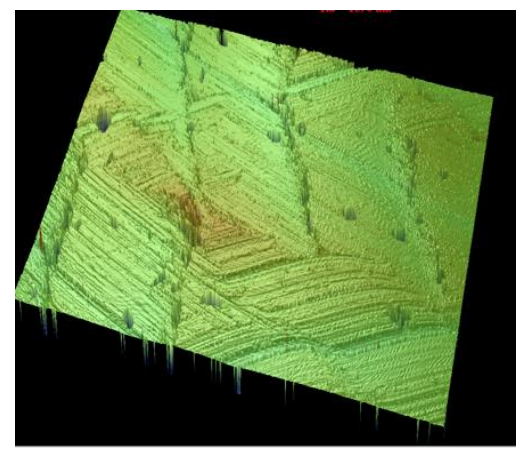

Test Run 9: $v_{\mathrm{s}} 95 \mathrm{~m} / \mathrm{min}, f_{\mathrm{z}} 0.20 \mathrm{~mm} / \mathrm{tooth}$, $\mathrm{a}_{\mathrm{p}} 0.30 \mathrm{~mm}$

Fig. 2: 3D surface topography images of milled slots

To assess the individual effects of each factor on $R_{a}$, parametric analysis has been carried out, as indicated in Figure 3. The figure demonstrates that the cutting speed and the feed rate both exhibited a linear trend with respect to surface roughness. In the case of $v_{\mathrm{s}}$, generally, larger values of $v_{\mathrm{s}}$ are expected to produce a smooth surface finish [2728]. This can be attributed to the fact that during the machining of this high strength alloy at high cutting speeds, a large amount of heat is generated. As nickel possesses a very low thermal conductivity $(11.2 \mathrm{~W} \mathrm{~m}-1 \mathrm{~K}-1)$ [25], the generated heat cannot dissipate effectively from the cutting region. Moreover, conventional cutting fluids cannot effectively flush away the heat from the cutting zone and tend to evaporate in the presence of high temperatures. The increase in the temperature and the cutting forces resulted in excessive tool wear, which eventually deteriorated the surface quality. Furthermore, high temperatures reduce the machinability of Inconel 718, due to its work-hardening characteristics which become more severe due to the presence of molybdenum and niobium alloying elements. Therefore, cutting of Inconel 718 at low $v_{s}$ is conventionally associated with high $\mathrm{R}_{\mathrm{a}}$, poor tool life, and the high cost of production.

In contrast, an interesting trend can be seen during the present experimentation; $R_{a}$ increases proportionally to $v_{\mathrm{s}}$. It is also evident from Table 5 and Figure 3 that the achieved $\mathrm{R}_{\mathrm{a}}$ is ranging from $0.5 \mu \mathrm{m}-1.9 \mu \mathrm{m}$ with the use of the Mecageen $450+$ flood condition approach. The roughness values achieved in this study are smaller than the values reported in previous studies [29-30]. Qiang et al. [29] compare the surface roughness results achieved during the milling of Inconel 718 under dry and MQL conditions. The roughness values range from $2.5 \mu \mathrm{m}-3.5 \mu \mathrm{m}$ in the case of dry machining and $2.0 \mu \mathrm{m}-2.6 \mu \mathrm{m}$ while machining under MQL environments. It is worth noting that the biodegradable oil, when integrated with the traditional flood approach, enables the process to produce better $R_{a}$ values, even at a low cutting speed, i.e. $65 \mathrm{~m} / \mathrm{min}$. This can be explained on the basis that the biodegradable oil, when applied in a flood condition, is able to penetrate into the tool chip intersection area and it develops a strong adhesive film of fatty acid chains which provides a sliding effect at the tool-workpiece contact point, thus lowering the tool chipping wear and eventually a better surface finish is achieved.

As far as feed rate $\left(f_{\mathrm{z}}\right)$ is concerned, the effect of $f_{\mathrm{z}}$ is an anticipated behavior which is consistent with other studies [5, 19]. In a previous study, Zahoor et al. [5] found that the machine spindle-force vibrations and $f_{\mathrm{z}}$ are the most effective parameters for $\mathrm{R}_{\mathrm{a}}$ during the milling of AISI P20 tool steel. It is attributed to a milling phenomenon in which the high $f_{\mathrm{z}}$ increases the distance between the two consecutive cuts leaving some uncut material behind on the workpiece surface which deteriorates the surface finish. Moreover, higher $f_{\mathrm{z}}$ contributes to the generation of chatter, which leads to high tool wear. Consequently, this results in poor surface finish.

However, the axial depth of cut $\left(a_{\mathrm{p}}\right)$ shows a nonlinear effect on surface roughness. Firstly, surface roughness tends 
to decrease, then increase. The parametric effect analysis concluded that $65 \mathrm{~m} / \mathrm{min} v_{\mathrm{s}}, 0.1 \mathrm{~mm} /$ tooth $f_{\mathrm{z}}$, and $0.3 \mathrm{~mm}$ $\mathrm{a}_{\mathrm{p}}$ produce a better surface finish of Inconel 718 .

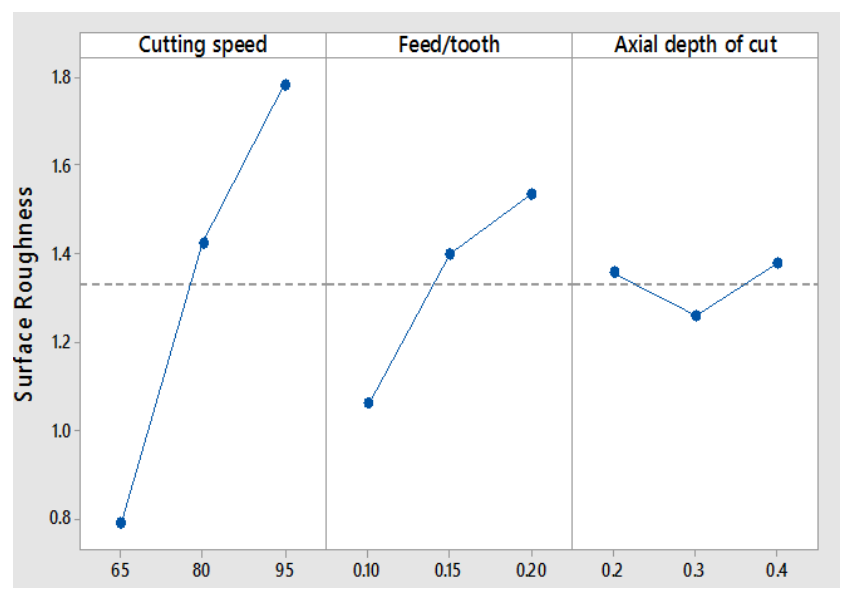

Fig. 3: Main effect plots for $\mathrm{R}_{\mathrm{a}}$

Additionally, analysis of variance (ANOVA) was performed at a $95 \%$ confidence interval to rule out the influential variables for $\mathrm{R}_{\mathrm{a}}$. As indicated in Table 6 , the $v_{\mathrm{s}}$ and the $f_{\mathrm{z}}$ are the most significant parameters with ${ }^{*} 79.44 \%$ and $18.79 \%$ contribution, respectively. It can also be noted that $a_{p}$ is proven statistically insignificant for $R_{a}$ as its $p$ value is greater than the set value of $\alpha$, which is 0.05 or $5 \%$. A similar behavior is reported by other studies $[6,29]$.

Table 6: ANOVA results for $\mathrm{R}_{\mathrm{a}}$

\begin{tabular}{|l|c|c|c|c|c|}
\hline Source & DF & Adj SS & Adj MS & F-Value & P-Value \\
\hline$v_{\mathrm{s}}$ & 2 & 1528844 & 764422 & 165.57 & 0.006 \\
\hline$f_{\mathrm{z}}$ & 2 & 361761 & 180880 & 39.18 & 0.025 \\
\hline $\mathrm{a}_{\mathrm{p}}$ & 2 & 24675 & 12337 & 2.67 & 0.272 \\
\hline Error & 2 & 9234 & 4617 & & \\
\cline { 1 - 4 } Total & 8 & 1924514 & \multicolumn{2}{|c|}{} \\
\cline { 1 - 3 }
\end{tabular}

$* \%$ Contribution (factor) $=\left[\operatorname{AdjSS}_{\text {(factor) }} / \operatorname{Adj~SS}(\right.$ total) $] \times 100$

\subsection{Tool Wear}

To improve the production efficiency, one approach is to enhance the tool life, which is also considered as one of the important criteria for the machinability of Inconel 718 . Figure 4 presents the optical micrographs of selected test runs where both primary and secondary flank wear can be observed. In the case of primary flank wear, chipping and flaking at the tool tip occur. While, during secondary flank wear grooving, built-up-edges (BUE), crater wear $\left(\mathrm{K}_{\mathrm{T}}\right)$ and flank wear $\left(V_{B}\right)$ are found on the cutter tip. From the figure, it is obvious that flaking and $V_{B}$ are the prominent tool wear types at minimum $v_{\mathrm{s}}$ during test run 1 . Whereas chipping, grooving, $\mathrm{K}_{\mathrm{T}}$, BUE, and $\mathrm{V}_{\mathrm{B}}$, are evident on the tip of the insert at maximum $v_{\mathrm{s}}$ used in test run 8 . One of the prime reasons for tool wear is the thermal softening that occurs during the machining of Inconel 718 at above $30 \mathrm{~m} / \mathrm{min}$ cutting speed with carbide tools [1]. Moreover, the presence of abrasive carbide particles in the tool material initiates the abrasion wear, which results in chipping of the tool tip. In addition, high temperature causes adhesion of workpiece material onto the rake face of the tool in the form of BUE. The calculated $V_{B}$ for all nine trials is given in Table 5. It is noted from the table that flank wear in each test is less than the standard tool life criteria (ISO 8688-2) for milling [5]. The maximum $\left(\mathrm{V}_{\mathrm{B}} 101.5 \mu \mathrm{m}\right)$ and minimum $\left(\mathrm{V}_{\mathrm{B}} 8.95 \mu \mathrm{m}\right)$ tool wear are achieved at 10 passes of $630 \mathrm{~mm}$ distance and at 15 passes of $945 \mathrm{~mm}$ distance, respectively. It may be attributed to the fact that the Mecagreen 450 oil reduces the coefficient of friction between the tool tip and workpiece material, thus, delaying the abrasion wear and resulting in longer tool life. It is also noted from the table that high values of both feed and cutting speed worsen the tool wear. 

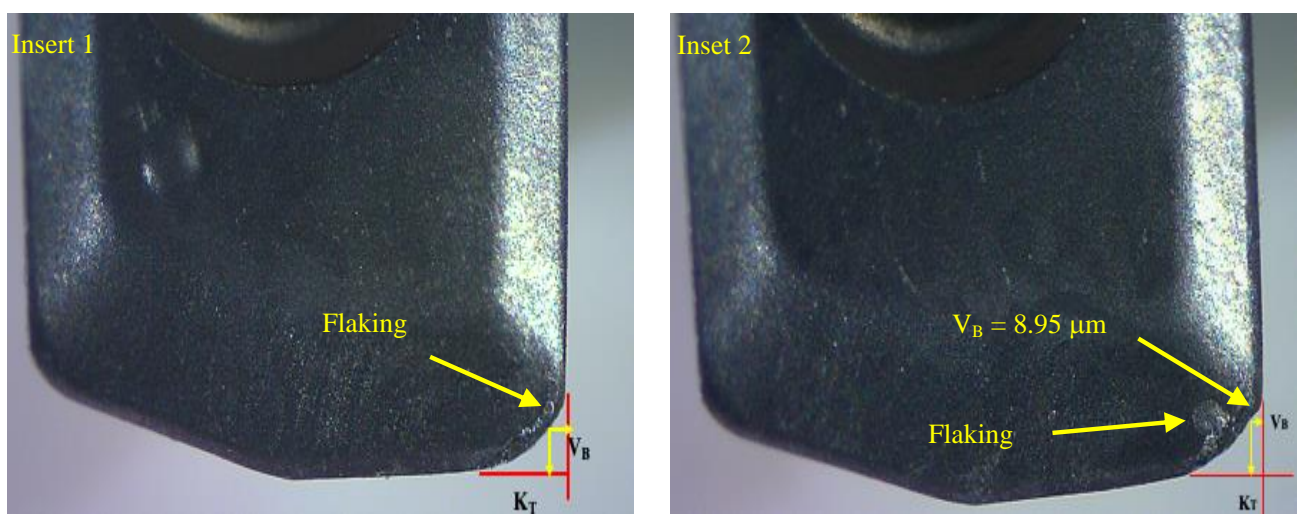

Test Run 1: $v_{\mathrm{s}} 65 \mathrm{~m} / \mathrm{min}, f_{\mathrm{z}} 0.10 \mathrm{~mm} / \mathrm{tooth}, \mathrm{a}_{\mathrm{p}} 0.20 \mathrm{~mm}$
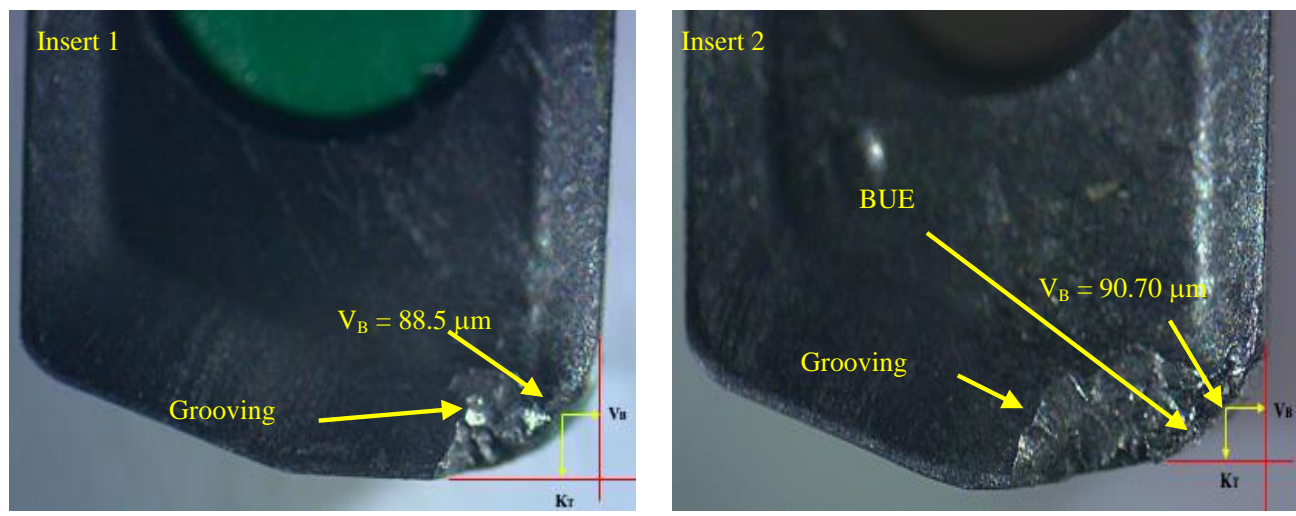

Test Run 8: $v_{\mathrm{s}} 95 \mathrm{~m} / \mathrm{min}, f_{\mathrm{z}} 0.15 \mathrm{~mm} / \mathrm{tooth}, \mathrm{a}_{\mathrm{p}} 0.20 \mathrm{~mm}$

Fig. 4: Optical micrographs of tool wear

To validate the optical micrograph results, scanning electron microscopy was carried out. For the sake of demonstration, SEM micrographs for test run 8 are presented in Figure 5(a-b). It is obvious from the figure that BUE and grooving wear exist on the cutter. Figure $5 \mathrm{~b}$ clearly indicates that workpiece material adheres to the tool surface. To supplement these findings further, phase detection analysis was performed using EDS and the results are shown in Figure 6. Three different points on the cutter surface were selected for the spectroscopy, i.e., point 1 at the BUE surface, point 2 at the tool surface without coating, and point 3 at the cutter surface with coating. The results of point 1 reveal the highest peak is $\mathrm{Ni}$ l $\alpha$ followed by smaller peaks of $\mathrm{C} k \alpha, \mathrm{N}_{\mathrm{b}} \mathrm{k} \alpha, \mathrm{C}_{\mathrm{r}} \mathrm{k} \alpha$, and $\mathrm{S}_{\mathrm{i}} \mathrm{k} \alpha$, confirming the presence of workpiece material. While, point 2 indicates the highest peak is $\mathrm{W} M \alpha$, which is the base material of the carbide inserts. Similarly, point 3 shows the highest peak is $\mathrm{Al} k \alpha$ followed by a smaller peak of Ti k $\alpha$, which is the coating material of the cutting inserts. 

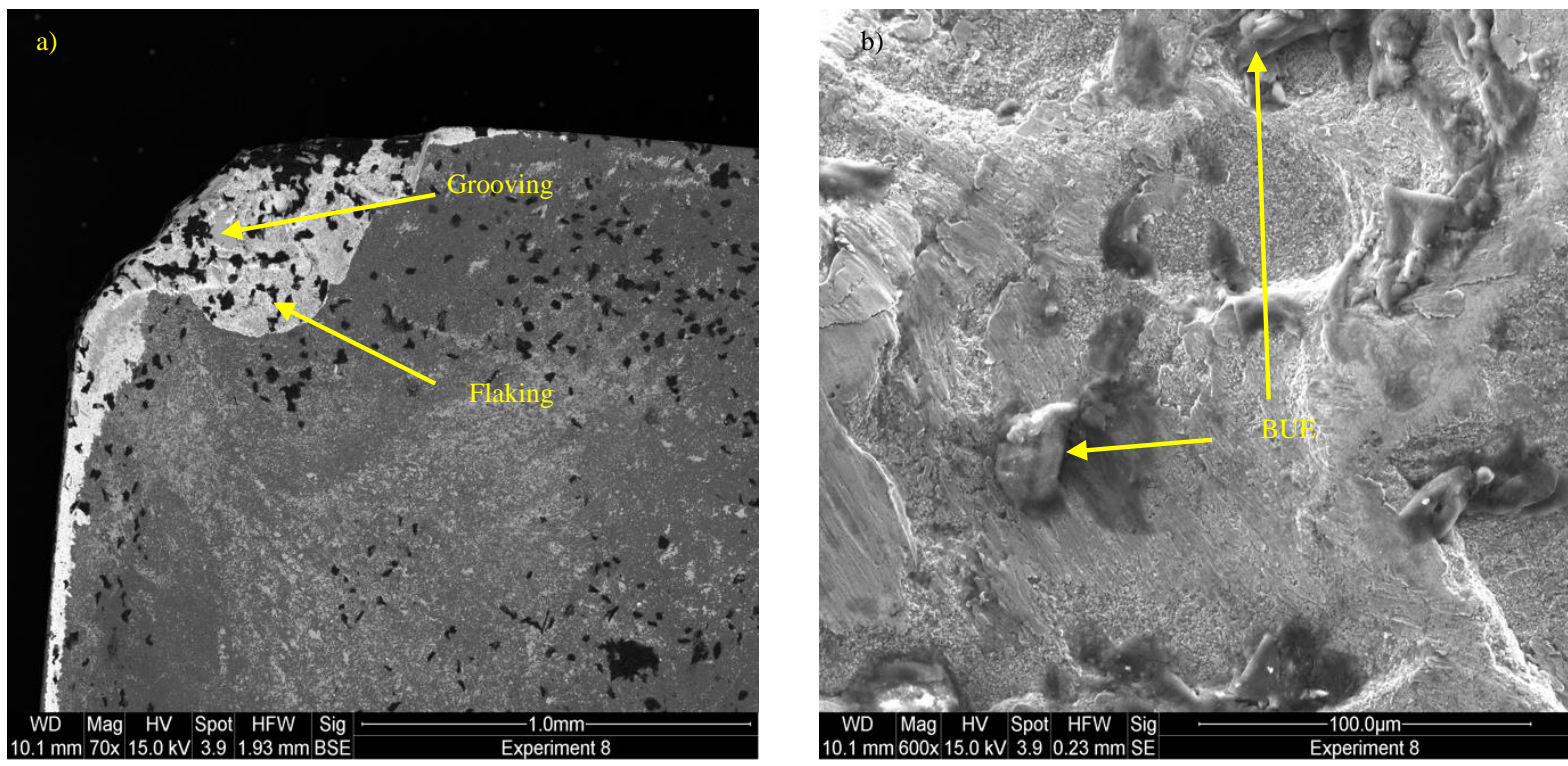

Test Run 8: $v_{\mathrm{s}} 95 \mathrm{~m} / \mathrm{min}, f_{\mathrm{z}} 0.15 \mathrm{~mm} / \mathrm{tooth}, \mathrm{a}_{\mathrm{p}} 0.20 \mathrm{~mm}$

Fig. 5: SEM micrographs for test run 8
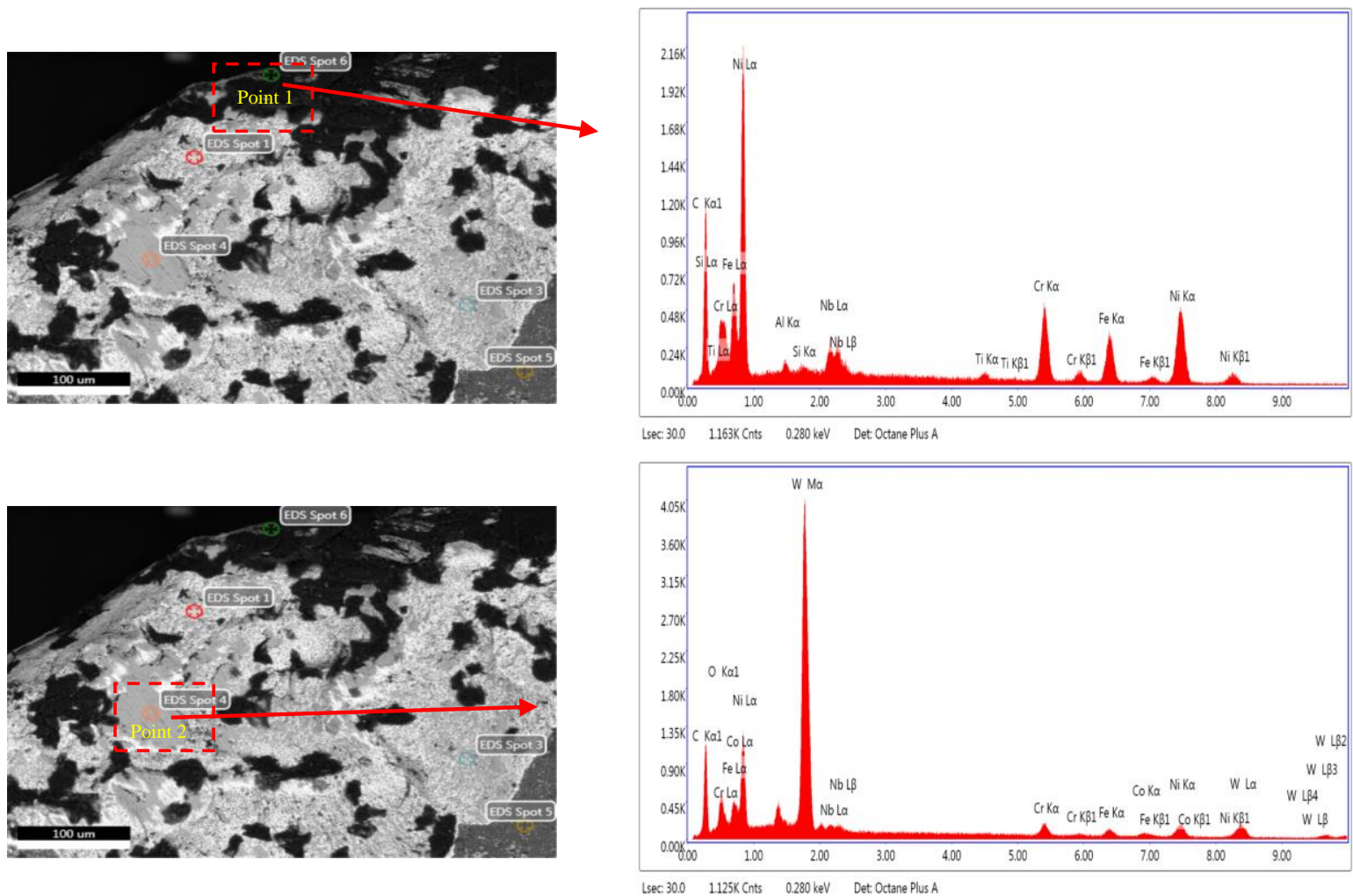


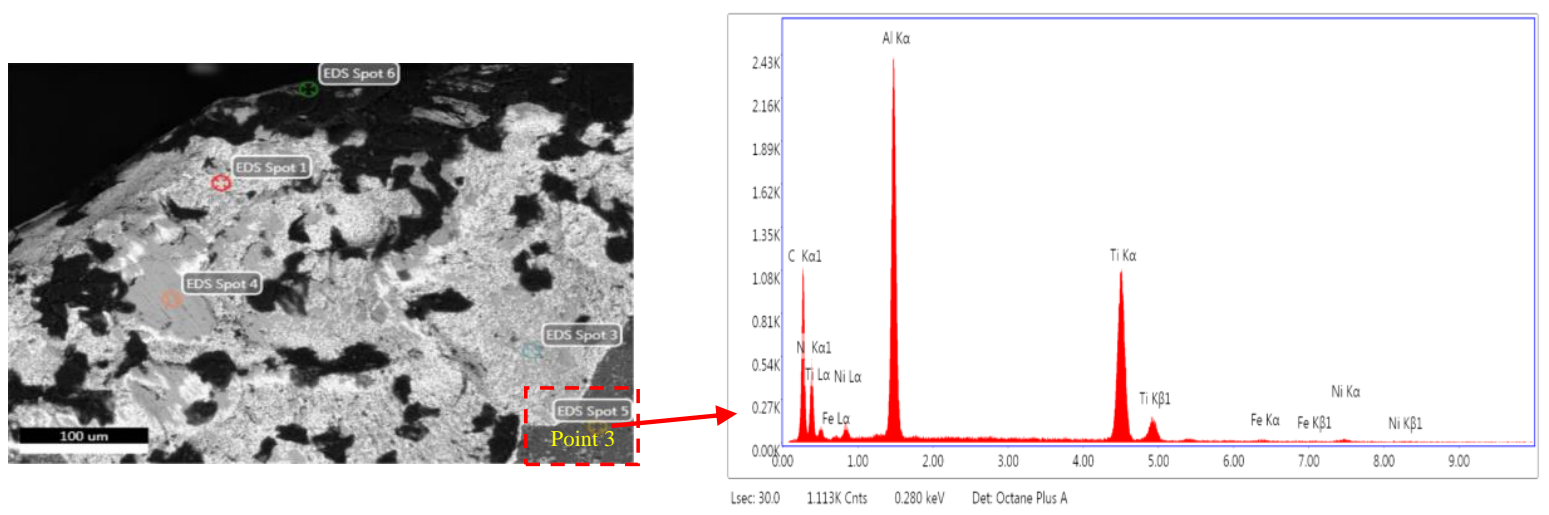

Fig. 6: EDS results for test run 8

To determine the significant factors affecting tool wear, ANOVA was conducted at a $95 \%$ confidence interval and results are listed in Table 7. It can be noted that the $v_{\mathrm{s}}$ and $f_{\mathrm{z}}$ are statistically significant with ${ }^{*} 87.5 \%$ and ${ }^{*} 9.1 \%$ contribution, respectively. These results are in agreement with the published work [31-32].

Table 7: ANOVA results for $\mathrm{V}_{\mathrm{B}}$

\begin{tabular}{|l|c|c|c|c|c|}
\hline Source & DF & Adj SS & Adj MS & F-Value & P-Value \\
\hline$v_{\mathrm{s}}$ & 2 & 882531 & 441266 & 230.96 & 0.004 \\
\hline$f_{\mathrm{z}}$ & 2 & 92030 & 46015 & 24.08 & 0.040 \\
\hline $\mathrm{a}_{\mathrm{p}}$ & 2 & 30475 & 15237 & 7.98 & 0.111 \\
\hline Error & 1 & 3821 & 1911 & & \\
\hline Total & 7 & 1008857 & & & \\
\hline
\end{tabular}

\subsection{Material Removal Rate, (MRR)}

The graphical representation of the material removal rate for each test run is presented in Figure 7. As illustrated in Figure 7 and Table 5, the maximum MRR (1668.63 $\left.\mathrm{mm}^{3} / \mathrm{min}\right)$ is achieved during test run 3 , when larger values of feed rate $(0.2 \mathrm{~mm} /$ tooth $)$ and axial depth of cut $(0.4 \mathrm{~mm})$ are used. In contrast, the small feed rate $(0.1 \mathrm{~mm} /$ tooth $)$ and axial depth of cut $(0.2 \mathrm{~mm})$ employed during test run 1 result in the minimum MRR $\left(527.90 \mathrm{~mm}^{3} / \mathrm{min}\right)$. It is worth mentioning that, irrespective of the cutting speed, high feed/tooth and axial depth of cut resulted in $68.36 \%$ more material removal rate $\left(\mathrm{MRR}_{\max }-\mathrm{MRR}_{\min } / \mathrm{MRR}_{\max } \times 100\right)$. These results are also confirmed by ANOVA, as given in Table 8, where $f_{\mathrm{z}}$ and $\mathrm{a}_{\mathrm{p}}$ are found to be statistically significant with ${ }^{*} 34.15 \%$ and ${ }^{*} 58.66 \%$ contribution, respectively. These results are consistent with published work [33-34]. It can be attributed to the fact that the linear motion of the tool increases at larger feed rates, which results into a decrease in the machining time. Whereas, the higher values of depth of cut yield greater chip thickness; therefore, the volume of material removed is enhanced.

Table 8: ANOVA results for MRR

\begin{tabular}{|l|c|c|c|c|c|}
\hline Source & DF & Adj SS & Adj MS & F-Value & P-Value \\
\hline$v_{\mathrm{s}}$ & 2 & 71263 & 35631 & 7.56 & 0.117 \\
\hline$f_{\mathrm{z}}$ & 2 & 383588 & 191794 & 40.70 & 0.024 \\
\hline $\mathrm{a}_{\mathrm{p}}$ & 2 & 658827 & 329414 & 69.90 & 0.014 \\
\hline Error & 2 & 9425 & 4713 & & \\
\hline Total & 8 & 1123104 & & & \\
\hline
\end{tabular}

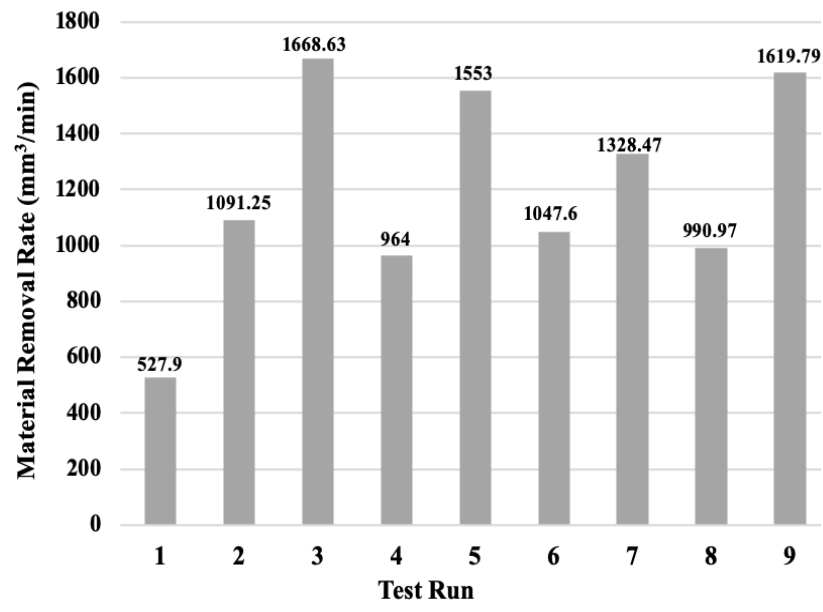

Fig. 7: Achieved material removal rate against each test run

\subsection{Cooling Strategy}

To compare the presently employed cooling strategy with others, the following are reported: the success of any cutting 
environment relies on two main elements, (i) the cooling fluid, and (ii) the appropriate cooling approach. In the case of cooling fluids, it is estimated that $20 \%-30 \%$ of the manufacturing costs for machining of hard-to-cut alloys are associated with the cutting fluids [35]. Therefore, the selection of the cutting fluid is critical. On the other hand, the cooling method itself adds to the cost, if any special equipment is required for its application.

The current approach demonstrates several advantages over existing strategies. As revealed by the results and discussion, it not only offers significant gains as compared to conventional methods utilizing mineral-based soluble fluids with respect to machining characteristics (surface roughness, tool wear, and material removal rate), but also provides cost reduction in terms of environmental safety, corrosion prevention, consumption, and disposal. In terms of machining gains, the minimum achieved surface roughness and flank wear values are $0.5 \mu \mathrm{m}$ and $8.95 \mu \mathrm{m}$ at a low cutting speed of $65 \mathrm{~m} / \mathrm{min}$.

Due to its biodegradable characteristics, it is environmentally friendly. Moreover, Mecagreen 450 possesses excellent lubricity as compared to traditional cutting fluids, thus, it protects the machine structure from corrosion [25]. As far as consumption is concerned, it is mixed with water in a $6 \%$ concentration ratio providing a $30-45 \%$ reduction in use as compared to mineral oils (10$20 \%$ concentration ratio). Furthermore, being a highpressure cutting fluid, it offers excellent foaming resistance, thus causing only a $10 \%$ loss of oil during its recycling. Additionally, the flood approach is a cost-effective choice as no dedicated equipment is required, as is the case for MQL and cryogenic cooling.

\section{Conclusions and Recommendations for Future \\ Research}

Conventional milling of Inconel 718 has been performed by employing biodegradable oil in flood condition. The following can be inferred based on the experimental results, parametric and microscopic analyses, and aforementioned discussion. (i) In order to obtain smaller values of surface roughness and tool wear, Mecagreen 450 in flood condition could be the appropriate cooling strategy for the machining of Inconel 718 at low cutting speeds. The minimum achieved surface roughness and flank wear values are $0.5 \mu \mathrm{m}$ and $8.95 \mu \mathrm{m}$ at $65 \mathrm{~m} / \mathrm{min}$.

(ii) With respect to surface roughness, cutting speed has been provided statistically as the most significant factor, with $74.44 \%$ contribution, followed by the feed/tooth, with $18.79 \%$ contribution. Moreover, the main effect plots reveal that $65 \mathrm{~m} / \mathrm{min} v_{\mathrm{s}}, 0.1 \mathrm{~mm} f_{\mathrm{z}}$, and $0.3 \mathrm{~mm} \mathrm{a}_{\mathrm{p}}$ produce the best surface finish, for the experimental conditions investigated.

(iii) With respect to tool wear, abrasion and adhesion wear have been observed as the prominent types of wear. These results are further validated by SEM and EDS analysis which confirmed the existence of flaking, tool chipping, grooving, BUE, and flank wear on the carbide inserts. The maximum flank wear $(101.50 \mu \mathrm{m})$ was achieved at 10 passes of $630 \mathrm{~mm}$ distance. Also, ANOVA proves that the cutting speed and feed/tooth are the influencing control variables with $87.5 \%$ and $9.1 \%$ contribution, respectively.

(iv) Irrespective of the cutting speed, high material removal rate $\left(1668.63 \mathrm{~mm}^{3} / \mathrm{min}\right)$ was achieved at higher values of $f_{\mathrm{z}}$ and $\mathrm{a}_{\mathrm{p}}$. ANOVA also confirms that the feed per tooth and the axial depth of cut are influential variables with $34.15 \%$ and $58.66 \%$ contribution, respectively.

The smaller values of $R_{a}$ and $V_{B}$ produced during the present experimentation indicate that the employed cooling strategy can potentially be used as an environmentally friendly cooling method for the milling of Inconel 718.

As far as the future of this research is concerned, the effects of various biodegradable oils integrated with flood condition can be considered to compare the improvement in terms of machining quality and environmental consciousness.

\section{Acknowledgement}


The authors would like to sincerely thank Dr. A. Alpas, the Director of the Tribology Research Center in the Department of Mechanical, Automotive and Materials, University of Windsor, Canada, for providing measurement facilities, and many constructive comments. The authors would like to acknowledge the financial support received from Natural Sciences and Engineering Research Council (NSERC).

\section{References}

1. Shokrani A., Dhokia V. \& Newman S. T. (2012) Environmentally conscious machining of difficult-to-machine materials with regard to cutting fluids. International Journal of Machine Tools and Manufacture. 57:83-101

2. Aslantas K., Cicek A. (2018) The effects of cooling/lubrication techniques on cutting performance in micro-milling of Inconel 718 superalloy. Procedia CIRP. 77:70-73

3. Zhao J., Liu Z., Shen Q., Wang B., Wang Q. (2018) investigation of cutting temperature during turning Inconel 718 with (TiAlN) PVD coated cemented carbides tool. Materials Basel. 11(8):1281

4. Ren X. P., Liu Z. Q. (2016) Influence of cutting parameters on work hardening behavior of surface layer during turning superalloy Inconel 718. International Journal of Advanced Manufacturing Technology. 86(5): 2319-2327

5. Zahoor S, Mufti NA, Saleem MQ, Mughal MP, Qureshi MAM (2017) Effect of machine tool's spindle forced vibrations on surface roughness, dimensional accuracy and tool wear in vertical milling of AISI P20. International Journal of Advanced Manufacturing Technology. 89: 3671-3679

6. Zahoor S., Mufti N.A., Saleem M.Q., Shehzad A. (2018) An investigation into surface integrity of AISI P20 machined under the influence of spindle forced vibration. International Journal of Advanced Manufacturing Technology. 96(9-12): 3565-3574

7. Zeilmann R.P., Fontanive F., Soares R. (2017) Wear mechanism during dry and wet turning of Inconel 718 with ceramic tools. International Journal of Advanced Manufacturing Technology. 92(5-8):2705-2714

8. Imran M., Mativenga P. T., Gholinia A., and Withers P. J. (2014) Comparison of tool wear mechanisms and surface integrity for dry and wet micro-drilling of nickel-base superalloys. International Journal of Machine Tools and Manufacture. 76: 49-60

9. Sharma J., Singh Sidhu B. (2014) Investigation of effects of dry and near dry machining on AISI D2 steel using vegetable oil. Journal of Cleaner Production. 66:619-623.

10. Shashidhara Y., Jayaram S. (2010) Vegetable oils as a potential cutting fluids evolution

11. Musfirah A.H, Ghani J.A., CheHaron C.H. (2017) Tool wear and surface integrity of Inconel 718 in dry and cryogenic coolant at high cutting speed. Wear. 376-377: 125-133

12. Mehta A., Hemkaumar S., Patil A., Khandke S. P., Kuppan P., Oyyaravelu R., Balan A.S.S. (2018) Influence of sustainable cutting environment of cutting forces, surface roughness and tool wear in turning of Inconel 718. Materials Today:Proceeding. 5(2):6746-6754

13. Leopardi G., Tagliaferri F., Rüger C., Dix (2015) Analysis of laser assisted milling (LAM) of Inconel 718 with ceramic tools. Procedia CIRP. 33: 514-519

14. Hafiz M.S.A., Kasim M.S., Mohamad W.N.F., Izamshah R., Aziz M.S.A., Akmal M., Othman I.S., Sundi S.A. (2018) Machinability ultrasonic assisted milling of Inconel 718 by Taguchi Method. ARPN Journal of Engineering and Applied Sciences. 13(20)
15. Fernandez V., Navas G., Sanda A., Bengoetxea I. (2018) Comparison of machining Inconel 718 with conventional and sustainable coolant.

16. Iturbe A., Hormaetxe E., Garay A., Arrazola P.J. (2016) Surface integrity analysis when machining Inconel 718 with conventional and cryogenic cooling: Procedia CIRP. 45:67-70

17. Pereira O., Martin-Alfonso J.E., Rodriguez A., Calleja A., Fernandez-Valdivielso A., Lopez de Lacalle L.N. (2017) Sustainability analysis of lubricant oils for minimum quantity lubrication based on their tribo-rheological performance. Journal of Cleaner Production. 164:1419-1429

18. Ameen F. (2018) Prediction of surface roughness and tool wear using artificial neural networks for the green machining of Inconel 718. M. A. Sc. thesis, University of Windsor, Canada

19. Marques A., Guimaraes C., Batista da Silva R., Fonseca M.P.C., Sale W.F., Machado A.R. (2016) Surface Integrity Analysis of Inconel 718 after Turning with Different Solid Lubricants Dispersed in Neat Oil Delivered by MQL. Procedia Manufacturing. 5: 609-620

20. Hegab H., Umer U., Soliman M., Kishawy H. A. (2018) Effects of nano-cutting fluids on tool performance and chip morphology during machining Inconel 718. The International Journal of Advanced Manufacturing Technology. 96:3449-3458

21. Nel A., David G., Alvarez P.J., Badesha S., Castranova V., Ferrari M., Godwin H., Grodzinski P., Morris J., Savage N., Scott N., Wiesner M. (2011) Nanotechnology Environmental, Health, and Safety Issues. In: Nanotechnology Research Directions for Societal Needs in 2020. Science Policy Reports, Springer, Dordrecht. 1:159-220

22. Hull M., Bowman D. (2010) Nanotechnology environmental health and safety. Risks, regulation and management [Access Online via Elsevier]

23. Srikant R.R., Ramana V.S.N.V. (2015) Performance evaluation of vegetable emulsifier based green cutting fluid in turning of American Iron and Steel Institute AISI1040 steel-an initiative towards sustainable manufacturing. Journal of Cleaner Production.108:104-109

24. Lawal S., Choudhury I., Nukman Y. (2014) Evaluation of vegetable and mineral oilin-water emulsion cutting fluids in turning AISI 434 steel with coated carbide tools. Journal of Cleaner Production. 66:610-618

25. http://www.specialmetals.com/divisions/huntington.html. Retrieved on April 2, 2019

26. https://www.condat-lubricants.com/product/metal-workingfluids/machining-cutting-fluids/mecagreen/. Retrieved on May 2, 2019

27. Kaynaka Y., Gharibib A., lmazb U., kluc U.K., Aslantasd K. (2018) A comparison of flood cooling, minimum quantity lubrication and high pressure coolant on machining and surface integrity of titanium Ti-5553 Alloy. Journal of Manufacturing Processes. 24:503-512

28. Lu X.H. Hu X.C., Wang H., Si L.K., Liu Y.Y. (2016) Research on the prediction model of micro-milling surface roughness of Inconel718 based on SVM. Industrial Lubrication and Tribology. 68(2): 206-211

29. Qiang L. Ya-dong G., Ming C., Ming-jun L. (2017) Research on surface integrity in milling Inconel 718 superalloy. International Journal of Advanced Manufacturing Technology. 1-4:1449-1463

30. Shokrani A., Newman S.T. (2018) Hybrid cooling and lubricating technology for CNC milling of Inconel 718 nickel alloy. Procedia CIRP. 77:215-218

31. Addona D.M.D., Rayker S.J., Narke M.M. (2017) High speed machining of Inconel 718: tool wear and surface roughness analysis. Procedia CIRP. 62:269-274 
32. Zhu D., Zhang X., Ding H. (2013) Tool wear characteristics in machining of nickel-based superalloys. International Journal of Machine Tools \& Manufacture. 64:60-77

33. Shihab S.K., Mubarak E.M.M. (2016) Evaluation of surface roughness and material removal rate in end milling of complex shape. Universal Journal of Mechanical Engineering. 4(3): 69-73

34. Lu X., Wang F., Xue L., Feng Y., Liang S. (2019) Investigation of material removal rate and surface roughness using multi-objective optimization for micro-milling of Inconel 718. Industrial lubrication and Tribology. 71(6): 787-794

35. Pusavec F., Kramar D., Krajnik P., Kopac J., (2010) Transitioning to sustainable production - part II: evaluation of sustainable machining technologies. Journal of Cleaner Production. 18: 12111221 